Western University

Scholarship@Western

Department of Economics Research Reports

Economics Working Papers Archive

1978

\title{
Inferior Equilibria in a Pure Flow Model with Adaptive Expectations
}

Neil Raymon

Follow this and additional works at: https://ir.lib.uwo.ca/economicsresrpt

Part of the Economics Commons

Citation of this paper:

Raymon, Neil. "Inferior Equilibria in a Pure Flow Model with Adaptive Expectations." Department of Economics Research Reports, 7821. London, ON: Department of Economics, University of Western Ontario (1978). 


\section{RESEARCH REPORT 7821}

INFERIOR EQUILIBRIA IN A PURE FLOW

MODEL WITH ADAPTIVE EXPECTATIONS

by

Neil Raymon

May, 1978 


\title{
Inferior Equilibria in a Pure Flow Mode1 \\ with Adaptive Expectations
}

\author{
Neil Raymon* \\ Department of Economics \\ University of California \\ Santa Barbara, California 93106 \\ U.S.A. \\ May, 1978
}

\begin{abstract}
This paper presents a dynamic model in which pessimistic expectations cause an atomistic economy with flexible prices to get stuck in an inferior equilibrium. The economy involves labor and two flow consumption goods, households which are 1dentical, competitive ut1lity maximizers and firms which are atomistic profit maximizers. Producers of one good formulate point sales expectations which adjust adaptively. Prices adjust in response to (possibly expectations-constrained) excess demands. In relative price terms, a unique Pareto-optimal equilibrium and a continuum of Pareto-inferior equilibria exist. Under various initial conditions involving prices and expectations, the economy converges to an inferior equilibrium.
\end{abstract}




\section{Introduction}

Consider the following story. An economy with atomistic agents is in a full-employment equilibrium. Something causes firms to have lowered sales expectations. These expectations lead to a lower employment level, which leads to lower household income, which leads to lower realized sales, which leads to a yet lower level of sales expectations, etc. This process converges to a depressed level of economic activity and welfare which, due to price rigidities, is at least a short-run equilibrium.

Such stories of self-fulfilling expectations raise the question of whether an atomistic economy can get stuck in an inferior equilibrium even if prices are fully flexible. ${ }^{1}$ In the present paper a dynamic model is presented in which this occurs. The model involves a barter economy with three $^{2}$ flow goods: labor and two consumption goods (goods one and two). Each period, households, assumed to be identical, competitive, myopic utility maximizers, and firms, assumed to be atomistic, myopic profit maximizers, contract for these commodities in a central marketplace. ${ }^{3}$ RecontractIng opportunities are limited so that a firm's realized profits may suffer due to the production of more [non-storable] output than can be sold. This provides an incentive for producers of good one to formulate sales expectations. 4 The idea here is that at the outset of any period $t$ each firm producing good one has a point expectation of period $t$ sales, $y^{e}(t)$, and plans to produce and sell the minimum of $y^{e}(t)$ and the unconstrained competitive profit maximizing level of output. In the model below, this configuration of individual profit maximizers with individual sales expectations is replaced by an aggregate supply process for good one involving aggregate competitive profit maximization and an aggregate point sales expectation. 
The price of each commodity adjusts in response to excess demand (positive or negative) for that commodity. The aggregate sales expectation adjusts in an adaptive manner but with a flexible speed of adjustment. 5 Conceptually, what results for this economy is a discrete time adjustment process in prices and the aggregate sales expectation. In the model developed in Section two below, a more convenient continuous time "approximation" is substituted for the discrete time process. 6

When the aggregate sales expectation constraint is binding, this is reflected in the demand for labor and in the supply of good one. In such cases, excess demand for labor and for good one, and hence price adjustment, directly reflect the aggregate sales expectation. As a result this economy has two types of equilibrium. One type--which is unique in terms of relative prices-minvolves production of good one at the aggregate competitive profit maximizing level 1.e., production of good one is not effectively constrained by the aggregate sales expectation. The second type-of which there is a one dimensional continum in terms of relative prices--involves production of good one being effectively constrained by the aggregate sales expectation. The fact that households are identical allows this set of equilibria to be totally ordered by the Pareto principle. Essentially what happens is that in any equilibrium of the second type, the aggregate sales expectation represents a quantity constraint on the population of households, so as this point expectation falls through the set of equilibria, the equilibrium utility of the representative household falls with it.

Finally, an assumption is made that when the aggregate sales expectation is binding, it adjusts slowly ${ }^{7}$ (and when the market in good one is near [partial] equilibrium, very slowly ${ }^{7}$ ) relative to the price of good one. This assumption, 
together with some additional technical assumptions, allows one to show that the economy can converge to a Pareto-inferior position. In particular, if expectations in the aggregate are pessimistic ${ }^{7}$ and if [relative] prices are near ${ }^{7}$ the equilibrium price vector which would cause household behavior to exactly confirm these pessimistic expectations, then the economy converges to a Pareto-inferior position.

The formal model is developed and discussed further in Section 2 below. The main existence, efficiency and stability results are stated and proved in Section 3.

\section{The Mode1}

Consider the barter economy discussed in the preceding section. Labor is the only productive input. There are no multiproduct firms. Aggregate supply of good one and the corresponding demand for labor are derived from the solution of

$$
\begin{aligned}
& \max _{X} p_{1} F_{1}(X)-p_{0} X \\
& \text { subject to (a) } F_{1}(X) \leq Y^{e} \\
& \text { and to } \quad \text { (b) } X \geq 0
\end{aligned}
$$

where $p_{0}$ is the accounting price of labor, $p_{1}$ is the accounting price of good one, $F_{I}$ is the aggregate production function for good one, $Y^{e}$ is the aggregate point sales expectation for good one and $\mathrm{X}$ is the quantity demanded of labor. Aggregate supply of good two and the corresponding demand for labor are derived from the solution of

(2) $\max _{X} \mathrm{p}_{2} \mathrm{~F}_{2}(\mathrm{X})-\mathrm{p}_{0} \mathrm{X}$

subject to $x \geq 0$ 
where $P_{2}$ is the accounting price of good two and $F_{2}$ is the aggregate production function for good two. The following assumptions are made on the functions $F_{i} \cdot 8$ A1. For $i=1,2, F_{1}$ is real-valued and defined on $\Omega^{1}$ and twice continuously differentiable on $\Omega_{+}^{1}$ with $F_{i}^{\prime}>0, F_{i}^{\prime \prime}<0, F_{i}(0)=0$, $\lim _{X \rightarrow 0^{+}} F_{1}^{\prime}(X)=+\infty, \lim _{X \rightarrow+\infty} F_{1}^{\prime}(X)=0$.

Denote the vector of accounting prices $\left(\mathrm{p}_{0}, \mathrm{p}_{1}, \mathrm{p}_{2}\right)$ by $\mathrm{p}$. Al implies that for any $p \gg 0$, there exist unique, positive solutions for (1) and (2). Let $T_{2}(p)^{9}$ be the solution for (2) (i.e., $T_{2}(p)$ is the aggregate competitive profit-maximizing employment level for producers of good two). Let $T_{1}(p)$ be the solution for (1) without the constraint (a), so that the aggregate quantity demanded of labor by producers of $\operatorname{good}$ one is $\min \left\{T_{1}(P), F^{-1}\left(Y^{e}\right)\right\}$. The aggregate quantity supplied of good two is therefore $F_{2}\left(T_{2}(p)\right)$, while that of good one is $\min \left\{F_{1}\left(T_{1}(p)\right), Y^{e}\right\}$. Al implies that for $p \gg 0, i=1$ or 2, $T_{1}(p)$ is homogeneous of degree zero in $p$ and once continuously differentiable with $\frac{\partial T_{1}}{\partial p_{0}}<0, \frac{\partial T_{1}}{\partial p_{1}}>0$. Additionally, $F_{i}^{\prime}\left(T_{1}(p)\right)=\frac{p_{0}}{p_{1}}$ and $\lim _{0} \rightarrow 0^{+}\left(T_{1}(p)-F_{i}\left(T_{1}(p)\right)\right)=+\infty$ for $p \gg 0,1=1$ or 2 .

For $\mathrm{p} \gg 0$, aggregate profit functions are given by

$$
\Pi_{1}\left(\mathrm{p}, \mathrm{Y}^{\mathbf{e}}\right) \equiv \mathrm{p}_{1} \min \left\{\mathrm{F}_{1}\left(\mathrm{~T}_{1}(\mathrm{p})\right), \mathrm{Y}^{\mathrm{e}}\right\}-\mathrm{p}_{0} \min \left\{\mathrm{T}_{1}(\mathrm{p}), \mathrm{Y}^{\mathrm{e}}\right\}
$$

$$
\begin{aligned}
& \Pi_{2}(p) \equiv p_{2} F_{2}\left(T_{2}(p)\right)-p_{0} T_{2}(p) . \\
& \Pi\left(p, Y^{e}\right) \equiv \Pi_{1}\left(p, Y^{e}\right)+\Pi_{2}(p)
\end{aligned}
$$

Al Implies that for $\left(p, Y^{e}\right)>0, \Pi_{1}\left(p, Y^{e}\right)>0$ and $\Pi_{2}(p)>0$.

The economy includes $n$ households with identical preferences and identical, nontradeable equity shares in firms. Households gain positive 
utility from consumption of goods one and two and from leisure, defined as the endowment of potential labor activity $\bar{l}$, minus the quantity of labor supplied, $l$. Households have perfect foresight with regard to the planned profits of firms. ${ }^{10}$ (Al1 profits are distributed.) The representative househöld makes consumption-demand and labor-supply decisions according to the solution of the following problem

$$
\left(\ell, c_{1}, c_{2}\right) U\left(\bar{l}-l, c_{1}, c_{2}\right)
$$

$$
\text { subject to } \mathrm{P}_{1} \mathrm{c}_{1}+\mathrm{P}_{2} \mathrm{c}_{2} \leq \mathrm{p}_{0} \ell+\pi\left(\mathrm{p}, \mathrm{Y}^{\mathrm{e}}\right)
$$

and to $0 \leq l \leq \bar{l}, c_{1} \geq 0, c_{2} \geq 0$

where $U$ is the household's utility function, $c_{1}$ is the quantity demanded of good one, $c_{2}$ is the quantity demanded of good two and

(5) $\pi\left(p, \mathrm{Y}^{\mathrm{e}},\right) \equiv \frac{\Pi\left(\mathrm{p}, \mathrm{Y}^{\mathrm{e}}\right)}{\mathrm{n}}$

is the representative household's share of aggregate profits. The following assumptions are made with respect to the utility function $U$.

A2. $U$ is real-valued and nonnegative $\left(\right.$ with $U(0)=0$ ) on $\Omega^{3}$, strictly quasiconcave and twice continuously differentiable on $\Omega_{++}^{3}$, and quasi-concave and continuously differentiable from above on $\Omega^{3}-\Omega_{+}^{3}$, with $U_{1}$ (the partial with respect to the $1^{\text {th }}$ argument, $1=0,1,2$ ) strictly positive on $\Omega_{++}^{3}$, with the one-sided $U_{i}^{+}$nonnegative on $\Omega^{3}$, and with $\lim _{c_{i} \rightarrow+\infty} U\left(\bar{l}-l, c_{1}, c_{2}\right)=+\infty$ for $\bar{l}-l>0, c_{1}>0, c_{2}>0,1=1$ or 2.

It is also assumed that for $p \gg 0, c_{1}\left(p, \pi\left(p, Y^{e}\right)\right)>0, c_{2}\left(p, \pi\left(p, Y^{e}\right)\right)>0$. A2 implies that for any $\mathrm{p} \gg 0, \mathrm{Y}^{\mathrm{e}} \geq 0$, exact $1 \mathrm{y}$ one solution $\left(\ell\left(p, \pi\left(p, Y^{e}\right)\right), c_{1}\left(p, \pi\left(p, Y^{e}\right)\right), c_{2}\left(p, \pi\left(p, Y^{e}\right)\right)\right)$ exists to the utility maximization problem (4). For $\left(\mathrm{p}, \mathrm{Y}^{\mathrm{e}}\right) \gg 0$, this solution is continuously differentiable in $\left(p, Y^{e}\right)$ wherever $\Pi\left(p, Y^{e}\right)$ is and otherwise continuous in $\left(p, Y^{e}\right)$. For $p \gg 0, Y^{e} \geq 0$, this solution is homogeneous of degree zero in 
p. For any $\left(p, Y^{e}\right) \gg 0$, the budget constraint in (4) holds with equality and there exists a $\lambda\left(p, Y^{e}\right)>0$ such that for $i=0,1,2$,

$$
\mathrm{U}_{1}\left(\mathrm{l}-\ell\left(\mathrm{p}, \pi\left(\mathrm{p}, \mathrm{Y}^{\mathrm{e}}\right)\right), c_{1}\left(\mathrm{p}, \pi\left(\mathrm{p}, \mathrm{Y}^{\mathrm{e}}\right)\right), \mathrm{c}_{2}\left(\mathrm{p}, \pi\left(\mathrm{p}, \mathrm{Y}^{\mathrm{e}}\right)\right)\right)=\lambda\left(\mathrm{p}, \mathrm{Y}^{\mathrm{e}}\right) \mathrm{p}_{1} \cdot \text { Finally, }
$$

A2 implies that for $\left(p, Y^{e}\right) \gg 0$, the weak axiom of revealed preference holds

for the individual household. 11

In addition to these standard implications of A2, the following less

standard implications are required in the seque $1 .{ }^{12}$

For any $p \in \Omega_{+}^{3}-\Omega_{++}^{3}$ and $Y^{e} \geq 0$ such that either $p_{0}>0$ or $\Pi\left(p, Y^{e}\right)>0$,

no (finite) solution exists to the utility maximization problem and the

following are true.

a. Given any such $\left(P, Y^{e}\right)$, for any sequence $\left.\left\{\mathrm{P}^{k}, Y^{e k}\right)\right\}$ approaching $\left(p, Y^{e}\right)$ with $\mathrm{p}^{\mathrm{k}} \gg 0$ all $\mathrm{k}$,

$$
\lim _{k \rightarrow+\infty}\left[\ell\left(p^{k}, \pi\left(p^{k}, Y^{e k}\right)\right)+c_{1}\left(p^{k}, \pi\left(p^{k}, Y^{e k}\right)\right)+c_{2}\left(p^{k}, \pi\left(p^{k}, Y^{e k}\right)\right)\right]=+\infty \text {. }
$$

b. Given any such $\left(p, Y^{e}\right)$ and any such sequence but now with $\left(p^{k}, Y^{e k}\right) \gg 0$ a11 k, $\left\{\mathrm{U}\left(\bar{l}-\ell\left(\mathrm{p}^{\mathrm{k}}, \pi\left(\mathrm{p}^{\mathrm{k}}, \mathrm{Y}^{\mathrm{ek}}\right)\right), c_{1}\left(\mathrm{p}^{\mathrm{k}}, \pi\left(\mathrm{p}^{\mathrm{k}}, \mathrm{Y}^{\mathrm{ek}}\right)\right), c_{2}\left(\mathrm{p}^{\mathrm{k}}, \pi\left(\mathrm{p}^{\mathrm{k}}, \mathrm{Y}^{\mathrm{ek}}\right)\right)\right)\right\}$ is unbounded.

Given the foregoing, the aggregate excess demand system for this economy is $Z^{O}\left(p, Y^{e}\right) \equiv \min \left\{T_{1}(p), F_{1}^{-1}\left(Y^{e}\right)\right\}+T_{2}(p)-L\left(p, \Pi\left(p, Y^{e}\right)\right)$

(7) $\quad \mathrm{Z}^{1}\left(\mathrm{p}, \mathrm{Y}^{\mathrm{e}}\right) \equiv \mathrm{c}_{1}\left(\mathrm{p}, \Pi\left(\mathrm{p}, \mathrm{Y}^{\mathrm{e}}\right)\right)-\min \left\{\mathrm{F}_{1}\left(\mathrm{~T}_{1}(\mathrm{p})\right), \mathrm{Y}^{\mathrm{e}}\right\}$

$\mathrm{Z}^{2}\left(\mathrm{p}, \mathrm{Y}^{\mathrm{e}}\right) \equiv \mathrm{c}_{2}\left(\mathrm{p}, \Pi\left(\mathrm{p}, \mathrm{Y}^{\mathrm{e}}\right)\right)-\mathrm{F}_{2}\left(\mathrm{~T}_{2}(\mathrm{p})\right)$

where $\mathrm{Z}^{1}\left(\mathrm{p}, \mathrm{Y}^{\mathrm{e}}\right)$ is the aggregate excess demand for $\operatorname{good} i, 1=0,1$, 2 , as a function of prices and expectations (with $Z\left(p, Y^{e}\right)$ being the column vector of the $\mathrm{Z}^{1}\left(\mathrm{p}, \mathrm{Y}^{\mathrm{f}}\right)$, and where $\mathrm{L}\left(\mathrm{p}, \Pi\left(\mathrm{p}, \mathrm{Y}^{\mathrm{e}}\right)\right) \equiv \mathrm{n} l\left(\mathrm{p}, \pi\left(\mathrm{p}, \mathrm{Y}^{\mathrm{e}}\right)\right)$ and $c_{i}\left(p, \Pi\left(p, Y^{e}\right)\right) \equiv n c_{i}\left(p, \pi\left(p, Y^{e}\right)\right), 1=1,2$. 
Definition 1. For any fixed $\mathrm{Y}^{\mathrm{e}} \geq 0$, an equilibrium for the system (7) is a vector $\bar{p}>0$ such that $z^{0}\left(\bar{p}, Y^{e}\right)=z^{1}\left(\bar{p}, Y^{e}\right)=z^{2}\left(\bar{p}, Y^{e}\right)=0$.

The following results are required in the sequel. ${ }^{13}$

a. For any fixed $Y^{e} \geq 0$, the system ( 7 ) is defined and continuous for $p \gg 0$, and is once continuously differentiable for $p \gg 0$ wherever $F_{1}\left(T_{1}(p)\right) \neq Y^{e}$. Additionally, for any fixed $Y^{e} \geq 0$ and $p \gg-0$, the system (7) is homogeneous of degree zero in p, satisfies Walras' Law: $\mathrm{pZ}\left(\mathrm{p}, \mathrm{Y}^{\mathrm{e}}\right)=0$, and satisfies the weak axiom of revealed preference (In the aggregate): For any equilibrium $\bar{p}$ and any nonequilibrium $p$, $\overline{\mathrm{p}} \mathrm{Z}\left(\mathrm{p}, \mathrm{Y}^{\mathrm{e}}\right)>0$.

b. The system (7) is not defined for $p \in \Omega^{3}-\Omega_{H^{*}}^{3}$ For any fixed $Y^{e}>0$, given $p \in \Omega^{3}-\Omega_{+}^{3}$, for any strictly positive sequence $\left\{p^{k}\right\}$ approaching p, $\lim _{k \rightarrow+\infty} \sum_{i=0}^{2} Z_{i}\left(p^{k}, Y^{e}\right)=+\infty$. For $Y^{e}=0$, given $p \in \Omega_{+}^{3}-\Omega_{++}^{3}$ with $p_{0}>0$, for any strictly positive sequence $\left\{p^{k}\right\}$ approaching $p$, $\lim _{k \rightarrow+\infty} \sum_{i=0}^{2} Z_{i}\left(p^{k}, Y^{e}\right)=+\infty$

Contracting for the three flow commodities takes place in a central marketplace. During any one period, a single price vector p emerges, agents behave in the optimizing fashions discussed above and some transactions are actually consummated. (All realized transactions occur at the emerging price vector p.) As indicated in the introduction, the incentive for producers of good one to form expectations arises from the fact that recontracting is 
limited in this economy. "The only assumptions made with respect to the configuration of binding contracts are: 1) contracting is voluntary, 2) In any period, actual income equals actual expenditure for each household, 3) In any period, realized profit is non-negative for each firm.

The nature of buyer and seller interaction and in particular how prices are set is left unexplained. The assumption is made that the relevant market forces governing price adjustments are represented by the excess demand system (7). For the present economy, in which transactions are actually consummated, this means that buyers and sellers compete extensively enough or more generally, that information flows are such that unrevised supplies and demands rather than realized-transactions-constrained supplies and demands determine price movements. ${ }^{14}$ For instance, even if households are on the long side of the labor market and must revise consumption demands accordingly, the pressure of the unrevised demands is still felt in the consumption goods markets. On the other hand, the present price adjustment assumption means that the pressure of the true supply and demand desires of producers of good one is not felt in the markets for labor and good one when sales expectation constraints are binding.

In addition to the assumption that price adjustment is governed by (7), the assumption is made that the aggregate point sales expectation $\mathrm{Y}^{\mathrm{e}}$ adjusts adaptively but with a flexible speed of adjustment. Formally, the complete dynamic model is given by ${ }^{15}$ 
(8)

$$
\begin{aligned}
& \dot{\mathrm{p}}_{0}=\mathrm{k}_{0}\left[\min \left\{\mathrm{T}_{1}(\mathrm{p}), \mathrm{F}_{1}^{-1}\left(\mathrm{Y}^{\mathrm{e}}\right)\right\}+\mathrm{T}_{2}(\mathrm{p})-\mathrm{L}\left(\mathrm{p}, \Pi\left(\mathrm{p}, \mathrm{Y}^{\mathrm{e}}\right)\right)\right] \equiv \mathrm{k}_{0} \mathrm{Z}^{0}\left(\mathrm{p}, \mathrm{Y}^{\mathrm{e}}\right) \\
& \dot{\mathrm{p}}_{1}=\mathrm{k}_{1}\left[\mathrm{C}_{1}\left(\mathrm{p}, \Pi\left(\mathrm{p}, \mathrm{Y}^{\mathrm{e}}\right)\right)-\min \left\{\mathrm{F}_{1}\left(\mathrm{~T}_{1}(\mathrm{p})\right), \mathrm{Y}^{\mathrm{e}}\right\}\right] \equiv \mathrm{k}_{1} \mathrm{Z}^{1}\left(\mathrm{p}, \mathrm{Y}^{\mathrm{e}}\right) \\
& \dot{\mathrm{p}}_{2}=\mathrm{k}_{2}\left[\mathrm{C}_{2}\left(\mathrm{p}, \Pi\left(\mathrm{p}, \mathrm{Y}^{\mathrm{e}}\right)\right)-\mathrm{F}_{2}\left(\mathrm{~T}_{2}(\mathrm{p})\right)\right] \equiv \mathrm{k}_{2} \mathrm{Z}^{2}\left(\mathrm{p}, \mathrm{Y}^{\mathrm{e}}\right) \\
& \dot{\mathrm{Y}}=\mathrm{H}^{\mathrm{e}}\left[\mathrm{C}_{1}\left(\mathrm{p}, \Pi\left(\mathrm{p}, \mathrm{Y}^{\mathrm{e}}\right)\right)-\mathrm{Y}^{\mathrm{e}}\right] \equiv \mathrm{H}^{\mathrm{e}}\left[\mathrm{Z}^{\mathrm{e}}\left(\mathrm{p}, \mathrm{Y}^{\mathrm{e}}\right)\right]
\end{aligned}
$$

with constants $k_{1}>0,1=0,1,2$, with $\mathrm{H}^{\mathrm{e}}[\cdot]$ continuous, sign-preserving and satisfying $\mathrm{H}^{e}[0]=0$, and with a "." over a varlable indicating the first derivative with respect to time $(t) .^{16}$ The following assumptions are made for this system.

A3. There exists a finite constant $b>\frac{1}{k_{1}}$ defining the set (9) $\quad \mathrm{R}=\left\{\left(\mathrm{p}, \mathrm{Y}^{\mathrm{e}}\right) \in \Omega_{++}^{4}: \sum_{i=0}^{2} \frac{\mathrm{p}_{i}^{2}}{\mathrm{k}_{1}} \leq \mathrm{b}\right\}$ such that

a. For any $\left(p^{0}, \mathrm{Y}^{\mathrm{e}^{0}}\right) \in \mathrm{R}$, there exists a unique, strictly positive solution $\left(p\left(t ;\left(p^{0}, Y^{e^{0}}\right)\right), Y^{e}\left(t ;\left(p^{0}, Y^{e^{0}}\right)\right)\right.$ to $(8)$, defined for all $t \geq 0$, continuous in $\left(p^{0}, Y^{e^{0}}\right)$ and with $Y^{e}\left(t ;\left(p^{0}, Y^{e^{0}}\right)\right)$ bounded above. b. For any $\left(p, Y^{e}\right) \in R$ such that $Y^{e}<F_{1}\left(T_{1}(p)\right)$,

$$
\begin{aligned}
& \frac{1}{\sqrt{k_{1} b}}\left|k_{1} z^{1}\left(p, Y^{e}\right)\right| z\left|H^{e}\left[Z^{e}\left(p, Y^{e}\right)\right]\right| \\
& \text { and when }\left|z^{1}\left(p, Y^{e}\right)\right|<1, \\
& \frac{\left|z^{1}\left(p_{2} Y^{e}\right)\right|}{\sqrt{k_{1} b}}\left|k_{1} Z^{1}\left(p, Y^{e}\right)\right| \geq\left|H^{e}\left[Z^{e}\left(p, Y^{e}\right)\right]\right|
\end{aligned}
$$

Given A1-A2 above, not a11 of A3a need be assumed but this is done for convenience. The boundedness of $\mathrm{Y}^{\mathrm{e}}\left(\mathrm{t} ;\left(\mathrm{p}^{0}, \mathrm{Y}^{e^{0}}\right)\right)$ must be assumed.

A3b is stronger than what is technically needed but admits a more reasonable economic interpretation than weaker assumptions. Roughly speaking, 
this assumption means that when sales expectations effectively constrain producers of good one, 1) sales expectations adjust more slowly than price In response to a nonzero excess demand for good one, and 2) producers of good one are particularly cautious in revising expectations in response to a nonzero excess demand when the market for good one is near [partial] equilibrium (1.e., the adjustment of expectations is at least "second order smal1" in excess demand when the market is near equilibrium).

\section{Existence, Efficlency and Stability Results}

The results for this model are straightforward. Theorem 1 concerns the existence of equilibria for the dynamic system (8). Restricting attention to price vectors in the unit simplex $s^{3}$, there exists exactly one unconstrained equilibrium $\left(\mathrm{p}^{*}, \mathrm{Y}^{\mathrm{e}^{*}}\right.$ ) and a continuum of expectations-constrained equilibria ... $\left(\bar{P}\left(Y^{e}\right), Y^{e}\right), Y^{e} \in\left(0, Y^{e^{*}}\right)$. Theorem 2 states that this set of equilibria can be completely ordered by the utility level of the representative household and that this equilibrium utility falls as $\mathrm{Y}^{\mathrm{e}}$ falls. Theorem 3 states that if the system begins in the region $R$ defined in (9) above, then either it converges to a unique equilibrium (in terms of relative prices and expectations level) or it converges to a point at which the system is not defined, with $\mathrm{P}_{0}=\mathrm{P}_{2}=\mathrm{Y}^{\mathrm{e}}=0, \mathrm{P}_{1}=\sqrt{\mathrm{k}_{1} \mathrm{~b}(0)}$ (where $\mathrm{b}(0)$ is defined below) and $\mathrm{a}$ utility level for the representative household of $U(\bar{l}, 0,0)$ (equal to the infemum of equilibrium utility levels). Finally Theorem 4 characterizes subsets of $R$ from which the system converges to equilibria (or the previously mentioned infemum point) which yleld lower equilibrium utility levels than $\left(\mathrm{P}^{*}, \mathrm{Y}^{\mathrm{e}^{*}}\right)$ 
Defintion 2. An equilibrium for the system (8) is a vector ( $\bar{p}, \bar{Y}$ ) with $\bar{p} \gg 0, \bar{Y}^{e} \geq 0$, such that $Z^{0}\left(\bar{p}, \bar{Y}^{e}\right)=Z^{1}\left(\bar{p}, \bar{Y}^{e}\right)=z^{2}\left(\bar{p}, \bar{Y}^{e}\right)=z^{e}\left(\bar{p}, \bar{Y}^{e}\right)=0$.

Theorem 1. Restricting attention to price vectors in the unit simplex $s^{3}$, the equilibrium set for (8) contains a unique, strictly positive element $\left(\mathrm{P}^{*}, \mathrm{Y}^{\mathrm{e}^{*}}\right)$ such that $\mathrm{Y}^{\mathrm{e}^{*}}=\mathrm{F}_{1}\left(\mathrm{~T}_{1}\left(\mathrm{P}^{*}\right)\right.$ ) and for every $\mathrm{Y}^{\mathrm{e}} \in\left(0, \mathrm{Y}^{\mathrm{e}^{*}}\right)$, a unique, strictly positive element which can be designated $\left(\overline{\mathrm{p}}\left(\mathrm{Y}^{\mathrm{e}}\right), \mathrm{Y}^{\mathrm{e}}\right)$ and which satisfies $Y^{e}<F_{1}\left(T_{1}\left(\bar{P}\left(Y^{e}\right)\right)\right)$. Finally, no equilibrium exists with $Y^{e}=0$ and $\lim \overline{\mathrm{p}}\left(\mathrm{Y}^{\mathrm{e}}\right)=(0,1 ; 0)$. $\mathrm{Y}^{\mathrm{e}} \rightarrow 0$

Proof: Consider the excess demand system without expectations

$$
\begin{aligned}
& \tilde{z}^{0}(p) \equiv T_{1}(p)+T_{2}(p)-L(p, \Pi(p)) \\
& \tilde{z}^{1}(p) \equiv C_{1}(p, \Pi(p))-F_{1}\left(T_{1}(p)\right) \\
& \tilde{z}^{2}(p) \equiv C_{2}(p, \Pi(p))-F_{2}\left(T_{2}(p)\right)
\end{aligned}
$$

where $\Pi(p) \equiv p_{1} F_{1}\left(T_{1}(p)\right)-p_{0} T_{1}(p)+p_{2} F_{2}\left(T_{2}(p)\right)-p_{0} T_{2}(p)$.

Using A1-A2 and their implications (see pp. 4-6 above), existence of an equilibrium price vector $p^{*} \in s_{+}^{3}$ for this system is proved by means of Brouwer's fixed point theorem, following the lines of Arrow and Hahn ([1], pp. 26-28 and 31-32). The uniqueness of $\mathrm{p}^{*}$ is proved by using the fact that under $\mathrm{A} 1-\mathrm{A} 2$, the weak axiom of revealed preference (in the aggregate) holds for (10) (see Arrow and Hahn ([1], p. 218)). Defining $\mathrm{Y}^{\mathrm{e}^{*}}$ by $\mathrm{Y}^{\mathrm{e}^{*}}=\mathrm{F}_{1}\left(\mathrm{~T}_{1}\left(\mathrm{p}^{*}\right)\right)$, obviously $\left(\mathrm{p}^{*}, \mathrm{Y}^{\mathrm{e}^{*}}\right)$ is an equilibrium for $(8)$.

Now consider the excess demand system with expectations((7) above) with any fixed $\mathrm{Y}^{\mathrm{e}}>0$. Then using the properties listed on $\mathrm{p} .7$ above, and again a fixed-point and weak axiom of revealed preference proof along the lines of Arrow and Hahn ([1], pp. 26-28, 31-32 and 218), there exists a unique $\overline{\bar{p}}\left(Y^{e}\right) \in s_{+}^{3}$ 
such that $\stackrel{p}{\mathrm{p}}\left(\mathrm{Y}^{8}\right)$ is an equilibrium for (7) (see Definition 1 on p. 7 above). Take $\mathrm{Y}_{1}^{\mathrm{e}} \geq \mathrm{Y}^{\mathrm{e}^{*}}$ in $(7)$ and suppose $\overline{\overline{\mathrm{p}}}\left(\mathrm{Y}_{1}^{\mathrm{e}}\right) \neq \mathrm{p}^{*}$. Then a contradiction arises, since $\mathrm{p}^{*}$ is clearly an equilibrium for $(7)$ when $\mathrm{Y}^{\mathrm{e}} \geq \mathrm{Y}^{\mathrm{e}^{*}}$, so that $\overline{\bar{p}}\left(Y_{1}^{e}\right) \neq \mathrm{p}^{*}$ violates uniqueness for $\mathrm{Y}^{\mathrm{e}}=\mathrm{Y}_{1}^{\mathrm{e}}$. Hence, for $\mathrm{Y}^{\mathrm{e}} \geq \mathrm{Y}^{\mathrm{e}^{*}}, \overline{\overline{\mathrm{p}}}\left(\mathrm{Y}^{\mathrm{e}}\right)=\mathrm{p}^{*}$. Now take $\mathrm{Y}_{1}^{\mathrm{e}} \in\left(0, \mathrm{Y}^{\mathrm{e}^{*}}\right)$ and suppose that $\overline{\overline{\mathrm{p}}}\left(\mathrm{Y}_{1}^{\mathrm{e}}\right)$ is such that $\mathrm{F}_{1}\left(\mathrm{~T}_{1}\left(\overline{\overline{\mathrm{P}}}\left(\mathrm{Y}_{1}^{\mathrm{e}}\right)\right)\right) \leq \mathrm{Y}_{1}^{\mathrm{e}}$. Then clearly $\overline{\overline{\mathrm{P}}}\left(\mathrm{Y}_{1}^{\mathrm{e}}\right)$ is an equilibrium for $(10)$. Since $\mathrm{F}_{1}\left(\mathrm{~T}_{1}\left(\overline{\overline{\mathrm{p}}}\left(\mathrm{Y}_{1}^{\mathrm{e}}\right)\right)\right) \leq \mathrm{Y}_{1}^{\mathrm{e}}<\mathrm{Y}^{\mathrm{e}^{*}}=\mathrm{F}_{1}\left(\mathrm{~T}_{1}\left(\mathrm{P}^{*}\right)\right)$ can only occur on $\mathrm{S}_{+}^{3}$ if

$\frac{\bar{p}_{1}\left(Y_{1}^{e}\right)}{\vec{P}_{0}\left(Y_{1}^{e}\right)}<\frac{p_{1}^{*}}{p_{0}^{*}}$, one has $\overline{\bar{p}}\left(Y_{1}^{e}\right) \neq p^{*}$, violating the uniqueness of $p^{*}$ for $(10$.$) .$ Hence, for $\mathrm{Y}^{\mathrm{e}} \in\left(0, \mathrm{Y}^{\mathrm{e}}\right), \overline{\overline{\mathrm{p}}}\left(\mathrm{Y}^{\mathrm{e}}\right)$ is such that $\left.\mathrm{Y}^{\mathrm{e}}<\mathrm{F}_{1}\left(\mathrm{~T}{ }_{1} \overline{\overline{\mathrm{p}}}\left(\mathrm{Y}^{\mathrm{e}}\right)\right)\right)$.

The upshot of all this is that 1) the only possible equilibrium for (8) with $\mathrm{p} \in \mathrm{S}_{+}^{3}$ and $\mathrm{Y}^{\mathrm{e}} \geq \mathrm{Y}^{\mathrm{e}^{*}}$ is $\left.\left(\mathrm{p}^{*}, \mathrm{Y}^{\mathrm{e}^{*}}\right), 2\right)$ for each $\mathrm{Y}^{\mathrm{e}} \in\left(0, \mathrm{Y}^{\mathrm{e}^{*}}\right)$, $\left.\overline{(\bar{P}}\left(Y^{e}\right), Y^{e}\right)$ is an equilibrium for $(8)$ and it is the only equilibrium for (8) with sales expectations at $\mathrm{Y}^{\mathrm{e}}$ and $\mathrm{p} \in \mathrm{S}_{+}^{3}$, and 3$) \mathrm{Y}^{\mathrm{e}^{*}}=\mathrm{F}_{1}\left(\mathrm{~T}_{1}\left(\mathrm{p}^{*}\right)\right.$ ) and for any $\mathrm{Y}^{\mathrm{e}} \in\left(0, \mathrm{Y}^{\mathrm{e}^{*}}\right), \mathrm{Y}^{\mathrm{e}}<\mathrm{F}_{1}\left(\mathrm{~T}_{1}\left(\overline{\overline{\mathrm{P}}}\left(\mathrm{Y}^{\mathrm{e}}\right)\right)\right)$. This set of equilibria for (8) w111 henceforth be designated by the set (11) $\mathrm{E}=\left\{\left(\mathrm{p}, \mathrm{Y}^{\mathrm{e}}\right) \in \mathrm{s}_{+}^{3} \mathrm{x}(0, \infty): \mathrm{Y}^{\mathrm{e}} \in\left(0, \mathrm{Y}^{\mathrm{e}^{*}}\right]\right.$ and $\left.\mathrm{p}=\overline{\mathrm{p}}\left(\mathrm{Y}^{\mathrm{e}}\right)\right\}$ where $\overline{\mathrm{p}}\left(\mathrm{Y}^{\mathrm{e}}\right) \equiv \overline{\mathrm{p}}\left(\mathrm{Y}^{\mathrm{e}}\right)$ on $\left(0, \mathrm{Y}^{\mathrm{e*}}\right]$.

Finally, consider the case of $\mathrm{Y}^{\mathrm{e}}=0$ for the system (7). The existence of an equilibrium $\left[\right.$ in $s_{+}^{3}$ ] for $(7)$ when $Y^{e}=0$ implies that $c_{1}(p, \pi(p, 0))=0$ at this equilibrium which contradicts the last part of A2 above. Hence no such equilibrium exists. Suppose that $\overline{\mathrm{p}}\left(\mathrm{Y}^{\mathrm{e}}\right)$ has a limit point $\tilde{\mathrm{p}} \gg 0$ as $\mathrm{Y}^{\mathrm{e}} \rightarrow 0$. Then the system (7) is defined and continuous at $\tilde{\mathrm{p}}$ and one can show that $\tilde{\mathrm{p}}$ is an equilibrium for (7) with $\mathrm{Y}^{e}=0$, a contradiction of the fact that no equilibrium for (7) exists when $Y^{e}=0$. Since $\bar{p}\left(Y^{e}\right)$ remains in the compact set $s^{3}$ for 
$\mathrm{Y}^{\mathrm{e}} \in\left(0, \mathrm{Y}^{\mathrm{e}^{*}}\right], \overrightarrow{\mathrm{P}}\left(\mathrm{Y}^{\mathrm{e}}\right)$ must have a limit point on the boundary of $\mathrm{S}^{3}$ as $\mathrm{Y}^{\mathrm{e}} \rightarrow 0$. Using b on p. 7 above, the conclusion is that

$$
\mathrm{Y}_{\mathrm{Y} \rightarrow 0}^{\lim \rightarrow 0} \overline{\mathrm{p}}\left(\mathrm{Y}^{e}\right)=(0,1,0) \cdot D
$$

Hence, when the economy is in equilibrium with $\mathrm{Y}^{\mathrm{e}}=\mathrm{Y}^{\mathrm{e}^{*}}$, activity is not effectively constrained by sales expectations, whereas when the economy is in equilibrium with $\mathrm{Y}^{\mathrm{e}}<\mathrm{Y}^{\mathrm{e}^{*}}$, sales expectations do constitute an effective constraint on economic activity. The comparative statics consequences of this constraint provide the subject of Theorem 2.

Let the representative household's utility at any equilibrium $\left(\overline{\mathrm{p}}\left(\mathrm{Y}^{e}\right), \mathrm{Y}^{e}\right)$ be given by

$$
\begin{aligned}
& \mathscr{U}\left(Y^{\mathbf{e}}\right) \equiv U\left(\bar{l}-\ell\left(\bar{p}\left(Y^{e}\right), \pi\left(\bar{p}\left(Y^{e}\right), Y^{e}\right)\right), c_{1}\left(\bar{p}\left(Y^{e}\right), \pi\left(\bar{p}\left(Y^{e}\right), Y^{e}\right)\right),\right. \\
& \left.c_{2}\left(\bar{p}\left(Y^{e}\right), \pi\left(\bar{p}\left(Y^{e}\right), Y^{e}\right)\right)\right) \text {. }
\end{aligned}
$$

The following assumption is needed. 17

A4. $\overline{\mathrm{p}}\left(\mathrm{Y}^{\mathrm{e}}\right)$ is continuously differentiable on $\left(0, \mathrm{Y}^{\mathrm{e}^{*}}\right)$.

Theorem 2. (Welfare at various equilibria.)

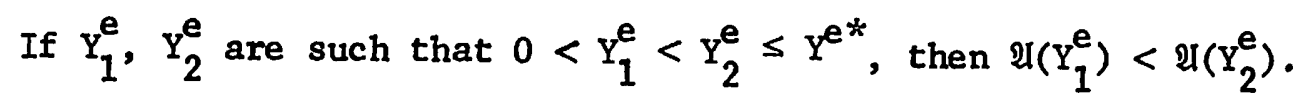

Additionally, $\lim \mathscr{U}\left(\mathrm{Y}^{\mathrm{e}}\right)=\mathrm{U}(\bar{l}, 0,0)$ and $\mathscr{U}\left(\mathrm{Y}^{\mathrm{e}}\right)>\mathrm{U}(\bar{l}, 0,0)$ for $\mathrm{Y}^{\mathrm{e}} \in\left(0, \mathrm{Y}^{\mathrm{e}^{*}}\right]$. $\mathrm{Y}^{\mathrm{e}} \rightarrow 0$

Proof. From Theorem 1, $F_{1}\left(T_{1}\left(\bar{P}\left(Y^{e}\right)\right)\right)>Y^{e}$ on $\left(0, Y^{e^{*}}\right)$. This, together with A4, Implies that $\mathscr{N}\left(Y^{e}\right)$ is [totally] differentiable in $Y^{e}$ on $\left(0, Y^{e^{*}}\right)$. Using first order conditions for utility maximization ((6) above), Walras' Law for (7)

(see $a$ on $\mathrm{p} .7$ above), the fact that $\mathrm{p}_{2} \mathrm{~F}_{2}^{\prime}\left(\mathrm{T}_{2}(\mathrm{p})\right)=\mathrm{p}_{0}$ and the fact that $F_{1}\left(T_{1}\left(\bar{p}\left(Y^{e}\right)\right)\right)>Y^{e}$ on $\left(0, Y^{e^{*}}\right)$, one easily deduces that on $\left(0, Y^{e^{*}}\right)$,

$$
\frac{d \mathscr{U}}{d Y^{e}}=\frac{\lambda}{n}\left[\bar{p}_{1}\left(Y^{e}\right)-\bar{P}_{0}\left(Y^{e}\right) \frac{d F_{1}^{-1}\left(Y^{e}\right)}{d Y^{e}}\right]>0 \text {. }
$$


Hence, using the mean value theorem, $\mathscr{U}\left(\mathrm{Y}^{\mathrm{e}}\right)$ is strictly increasing on $\left(0, \mathrm{Y}^{\mathrm{e}^{*}}\right]$. Consider the second part of the statement of Theorem 2. That $\mathscr{U}\left(Y^{e}\right)>U(\bar{l}, 0,0)$ for $Y^{e} \in\left(0, Y^{e^{*}}\right]$ follows from the fact that $\pi\left(Y^{e}, \bar{p}\left(Y^{e}\right)\right)>0$ for $\mathrm{Y}^{\mathrm{e}}>0$, the fact that the solution to the utility maximization problem (4) above when profit income is positive yields utility not less than $U(\bar{l}, 0,0)$ and the last part of A2. That $\operatorname{Iim} \mathscr{U}\left(Y^{e}\right)=U(\bar{l}, 0,0)$ follows from the fact that $\mathrm{Y}^{\mathrm{e}} \rightarrow 0$

U has a limit as $\mathrm{Y}^{\Theta} \rightarrow 0$ (since $\mathscr{U}$ is strictly increasing on $\left(0, \mathrm{Y}^{\mathrm{e}^{*}}\right.$ ) and bounded below by A2) and from the last part of Theorem 1. $D$ In equilibrium, pessimistic sales expectations (1.e., $\mathrm{Y}^{\mathrm{e}}<\mathrm{Y}^{\mathrm{e}^{*}}$ ) induce a kind of rationing in good one which is, in a static sense, the source of suboptimality. This is reflected in (13) above: at any equilibrium $\left(\overline{\mathrm{p}}\left(\mathrm{Y}^{\mathrm{e}}\right), \mathrm{Y}^{\mathrm{e}}\right)$ with $\mathrm{Y}^{\mathrm{e}}<\mathrm{Y}^{\mathrm{e}^{*}}$, marginal social benefit of good one per capita $\left(\frac{\lambda-}{\mathrm{P}}{ }_{1}\left(\mathrm{Y}^{\mathrm{e}}\right)\right)$ is greater than marginal social cost of good one per capita $\left.\left(\frac{\lambda-\bar{p}_{0}}{\mathrm{P}^{e}}\right) \frac{\mathrm{dF}_{1}^{-1}\left(\mathrm{Y}^{\mathrm{e}}\right)}{d \mathrm{Y}^{e}}\right)$ and this difference is equal to the marginal net social benefit per capita of rising sales expectations $\left(\frac{d \mathscr{U}}{d Y^{e}}\right)$.

Due to the homogeneity properties of $(7)$ and $(10)$, for any $\beta>0$. $\mathrm{Y}^{\mathrm{e}} \in\left(0, \mathrm{Y}^{\mathrm{e}}\right],\left(\overline{\beta \mathrm{p}}\left(\mathrm{Y}^{\mathrm{e}}\right), \mathrm{Y}^{\mathrm{e}}\right)$ is an equilibrium for $(8)$ and the representative household's ut1lity at $\left(\overline{\beta p}\left(Y^{e}\right), Y^{e}\right)$ is just $\mathscr{R}\left(Y^{e}\right)$. Let the full-dimensional set of equilibria for (8) be denoted by $\varepsilon \subset \Omega_{++}^{4}$.

For any time path $\left(p\left(t ;\left(p^{0}, Y^{e^{0}}\right)\right), Y^{e}\left(t ;\left(p^{0}, Y^{e^{0}}\right)\right)\right),\left(p^{0}, Y^{e^{0}}\right) \in R$ (see $A 3$ above), define $b\left(t ;\left(p^{0} Y^{0}\right)\right.$ ) by 
(14) $\sum_{i=0}^{2} \frac{\left[p_{i}(t)\right]^{2}}{k_{i}}=b(t)$,

where dependence on $\left(\mathrm{p}^{0}, \mathrm{Y}^{\mathrm{e}^{0}}\right.$ ) is suppressed, and let

$$
B(0)=\left\{p \in \Omega_{+}^{3}: \sum_{i=0}^{2} \frac{p_{i}^{2}}{k_{i}}=b(0)\right\},
$$

where again, dependence on $\left(\mathrm{p}^{0}, \mathrm{Y}^{\mathrm{e}^{0}}\right)$ is suppressed.

One can easily show, using Walras' Law and (8), that for all $t \geq 0$, $\mathrm{p}(t) \in \mathrm{B}(0) .0^{18}$ Then for each $\mathrm{Y}^{\mathrm{e}} \in\left(0, \mathrm{Y}^{\mathrm{e}^{*}}\right]$, there exists a unique $\beta\left(Y^{e}, B(0)\right)>0$ such that $\beta\left(Y^{e}, B(0)\right) \bar{p}\left(Y^{e}\right) \in B(0)$. Hence, for any $\left(P^{0}, Y^{e^{0}}\right) \in R$, the relevant equilibrium set for $(8), \varepsilon \cap B(0)$, is given by

$$
E\left(\mathrm{P}^{0}, \mathrm{Y}^{\mathrm{e}^{0}}\right) \equiv\left\{\left(\mathrm{p}, \mathrm{Y}^{\mathrm{e}}\right) \in \mathrm{B}(0) \times\left(0, \mathrm{Y}^{\mathrm{e}^{*}}\right]: \mathrm{p}=\beta\left(\mathrm{Y}^{\mathrm{e}}\right) \overline{\mathrm{P}}\left(\mathrm{Y}^{\mathrm{e}}\right)\right\}
$$

(various dependencies suppressed).

Theorem 3. (Local asymptotic stability of (8)). The system (8) is asymptotically stable on $R$ 'in the sense that for any initial point $\left(p^{0}, Y^{e^{0}}\right) \in R$, either $\left(P(t), Y^{e}(t)\right)$ converges to a point in $E\left(p^{0}, Y^{e^{0}}\right)$ or it converges to the point $\left(\mathrm{p}, \mathrm{Y}^{\mathrm{e}}\right)$ with $\mathrm{p}_{0}=\mathrm{p}_{2}=\mathrm{Y}^{\mathrm{e}}=0$ and $\mathrm{p}_{1}=\sqrt{\mathrm{k}_{1} \mathrm{~b}(0)}$, where $\mathrm{b}(0)$ is as in (14) above. Proof. For any $\left(p^{0}, Y^{e^{0}}\right) \in R$, let $\left(p(t), Y^{e}(t)\right)$ be the solution path the characteristics of which are given in $A 3$ above (where dependence on $\left(p^{0}, Y^{e^{0}}\right.$ ) is suppressed). Note that because of the assumed boundedness of $Y^{e}(t)$ and the fact that $p(t) \in B(0)$ (see above), $\left(p(t), Y^{e}(t)\right.$ ) remains in a set $S\left(p^{0}, Y^{e^{0}}\right) \subset R$ the closure of which is compact in $\Omega_{+}^{4}$ and which satisfies: $\left(p, Y^{e}\right) \in S\left(p^{0}, Y^{e^{0}}\right)$ implies $p_{1} \leq \sqrt{k_{1} b}$. 
Let $\pi(t)$ ' be the individual household's share of profits at time $t$ on the solution path and consider the function

$$
\mathrm{u}(\mathrm{t})=\mathrm{U}\left(\bar{l}-\ell(\mathrm{p}(\mathrm{t}), \pi(\mathrm{t})), \mathrm{c}_{1}(\mathrm{p}(\mathrm{t}), \pi(\mathrm{t})), \mathrm{c}_{2}(\mathrm{p}(\mathrm{t}), \pi(t))\right) . \text { This }
$$

function is continuous on any solution path and is differentiable in $t$ expect where $Y^{e}(t)=F_{1}\left(T_{1}(P(t))\right)$.

case 1: $t \in[0, \infty)$ such that $Y^{e}(t)>F_{1}\left(T_{1}(p(t))\right)$ and such that

$\left(p(t), Y^{e}(t)\right) \notin E^{0}$, where for the remainder of the proof, $E\left(p^{0}, Y^{e^{0}}\right)$ is denoted by $E^{0}$.

For such $t$, one can easily show 19 that

$\dot{u}(t)=-\frac{\lambda}{n} \sum_{i=0}^{2} k_{i}\left[Z^{i}\left(p(t), Y^{e}(t)\right)\right]^{2} \leq 0$

where $\lambda>0$ is as in (6) above and where equality holds if and only if $p(t)=\beta\left(Y^{e^{*}}\right) p^{*} \equiv p^{* *} \in B(0)$. If this last occurs with $Y^{e}(t)>F_{1}\left(T_{1}(p(t))\right)$, then one can easily show that $\left(p(t), Y^{e}(t)\right.$ ) converges to $\left(p^{* *}, Y^{e^{*}}\right) \in E^{0}$. Hence, for any time $t$ covered in this first case, $\dot{u}(t)<0$ unless the system converges to $\left(\mathrm{p}^{* *}, \mathrm{Y}^{\mathrm{e}}\right)$.

case 11: $t \in[0, \infty)$ such that $Y^{e}(t)<F_{1}\left(T_{1}(p(t))\right)$ and such that

$$
\left(p(t), Y^{e}(t)\right) \notin E^{0} \text {. }
$$

Using essentially the same method as that used to derive the equality

in (17) and the fact that $\mathrm{Y}^{\mathrm{e}}(\mathrm{t})<\mathrm{F}_{1}\left(\mathrm{~T}_{1}(\mathrm{P}(\mathrm{t}))\right)$ implies

$Z^{1}\left[P(t), Y^{e}(t)\right]=Z^{e}\left[P(t), Y^{e}(t)\right]$, one has

$$
\begin{aligned}
\dot{u}(t)= & -\frac{\lambda}{n}\left\{\sum_{1}^{2} k_{i}\left[Z^{i}\left(p(t), Y^{e}(t)\right)\right]^{2}\right. \\
& \left.-\left[P_{1}(t)-p_{0}(t) \frac{d F_{1}^{-1}\left(Y^{e}(t)\right)}{d Y^{e}}\right] H^{e}\left[Z^{1}\left(p(t), Y^{e}(t)\right)\right]\right\}<0
\end{aligned}
$$

where for $\mathrm{Z}^{1}\left[\mathrm{p}(t), \mathrm{Y}^{\mathrm{e}}(t)\right]<0$, the inequality follows from the fact that

$Y^{e}(t)<F_{1}\left(T_{1}(p(t))\right)$ implies $p_{1}(t)-p_{0}(t) \frac{d F_{1}^{-1}\left(Y^{e}(t)\right)}{d Y^{e}}>0$, and for

$\mathrm{Z}^{1}\left[\mathrm{P}(\mathrm{t}), \mathrm{Y}^{\mathrm{e}}(t)\right]>0$; the inequality follows from $\mathrm{A} 3 \mathrm{~b}$ and the fact that $\sqrt{k_{1} b}>p_{1}(t) .^{20}$ 
case 1ii: $t \in[0, \infty)$ such that $\mathrm{Y}^{\mathrm{e}}(\mathrm{t})=\mathrm{F}_{1}\left(\mathrm{~T}_{1}(\mathrm{p}(\mathrm{t}))\right)$ and such that $\left(p(t), Y^{e}(t)\right) \notin E^{0}$.

For any open interval on which this is true, $u(t)$ is again differentiable In $t$ and one can simply use the approach for case $i$ to gain $\dot{u}(t)<0$. Suppose alternatively that $t$ is an isolated point such that $\mathrm{Y}^{\mathrm{e}}(t)=\mathrm{F}_{1}\left(\mathrm{~T}_{1}(\mathrm{p}(\mathrm{t}))\right)$ and such that $\left(P(t), Y^{e}(t)\right) \notin E^{0}$. Then it is the case that for some interval $\left(t^{\prime}, t^{\prime \prime}\right), t \in\left(t^{\prime}, t^{\prime \prime}\right), \dot{u}(t)<0$ on $\left(t^{\prime}, t\right)$ and $\left(t, t^{\prime \prime}\right)$. But then by the mean value theorem, $u(t)$ must also be strictly decreasing at $t$.

Hence, either $\left(P(t), Y^{e}(t)\right)$ converges to $\left(p^{* *}, Y^{e^{*}}\right)$, and the proof is done, or $\mathrm{u}(\mathrm{t})$ is strictly decreasing along $\left(\mathrm{P}(\mathrm{t}), \mathrm{Y}^{\mathrm{e}}(\mathrm{t})\right)$. Suppose the latter. Then, since $u(t)$ is bounded below by zero (by A2), $u(t)$ has a $\operatorname{limit} \hat{u} \in[0, u(0)]$. As mentioned above $\left(p(t), Y^{e}(t)\right)$ remains in $S\left(p^{0}, Y^{e^{0}}\right)$ the closure of which is compact in $\Omega_{+}^{4}$. Hence $\left(p(t), Y^{e}(t)\right)$ has a limit point in the closure of $S\left(p^{0}, Y^{e^{0}}\right)$. Suppose $\left(\mathrm{P}(t), \mathrm{Y}^{\mathrm{e}}(t)\right)$ has a limit point $\left(\hat{\mathrm{P}}, \hat{\mathrm{Y}}^{\mathrm{e}}\right) \in \mathrm{R}$. Then there is a sequence $\left\{\left(p\left(t_{k}\right), Y^{e}\left(t_{k}\right)\right)\right\}$ converging to $\left(\hat{p}, \hat{Y}^{e}\right)\left(a s k, t_{k} \rightarrow \infty\right)$, and an argument analogous to that used by Uzawa ([8], p. 620) establishes that ( $\hat{p}, \hat{Y}^{e}$ ) is an equilibrium. Furthermore, this same argument establishes that $\hat{\mathrm{u}}=\mathscr{U}\left(\hat{\mathrm{Y}}^{\mathrm{e}}\right)$. But there is only one point in $E^{0}$ which gives this utility level. Hence, $(\hat{P}, \hat{Y}$ ) is unique.

Clearly, in this case, $\left(\mathrm{P}(\mathrm{t}), \mathrm{Y}^{\mathrm{e}}(\mathrm{t})\right)$ cannot also have a limit point in the closure of $S\left(\mathrm{P}^{0}, \mathrm{Y}^{\mathrm{e}^{0}}\right.$ ) but not in $\mathrm{R}$. (Such a point could only be $\left(\tilde{\mathrm{p}}, \tilde{\mathrm{Y}}^{e}\right.$ ) with $\tilde{\mathrm{p}}_{0}=\tilde{\mathrm{p}}_{2}=\tilde{\mathrm{Y}}^{\mathrm{e}}=0$ and $\tilde{\mathrm{p}}_{1}=\sqrt{\mathrm{k}_{1} \mathrm{~b}(0)}$, by the definition of $\mathrm{R}, \mathrm{b}$ on p. 6 above and the fact that $u(t) \leq u(0)<+\infty$. However, if $\left(\tilde{p}, \tilde{Y}^{e}\right)$ were a limit point, then by the latter part of Theorem 2, the fact that $u(t)$ has a IImit, and the limit assumption in $A 2$, one would have $\lim _{t \rightarrow \infty} u(t)=U(\bar{l}, 0,0)<\mathscr{U}\left(Y^{\mathrm{e}}\right)$ for any $\mathrm{Y}^{\mathrm{e}} \in\left(0, \mathrm{Y}^{\mathrm{e}^{*}}\right\}$, contradicting the fact established in the previous paragraph that $\lim _{t \rightarrow \infty} u(t)=\mathscr{U}\left(\hat{Y}^{e}\right)$ for some $\left.\hat{Y}^{e} \in\left(0, Y^{e^{*}}\right].\right)$ Hence, if 
$\left(p(t), Y^{e}(t)\right)$ has a limit point in $R$, it has a limit in $R$ which is a unique equilibrium point in $\mathrm{E}^{0}$.

Suppose alternatively that $\left(p(t), Y^{e}(t)\right)$ has no limit points in $R$. Then $\left(p(t), Y^{e}(t)\right)$ has a limit point in the closure of $S\left(p^{0}, Y^{e^{0}}\right)$ but not in $R$, and again, that limit point must have $P_{0}=p_{2}=Y^{e}=0$ and $\mathrm{p}_{1}=\sqrt{\mathrm{k}_{1} \mathrm{~b}(0)}$. This completes the proof of Theorem 3 . clearly, from the proof of Theorem 3, if the system begins at $\left(\mathrm{p}^{0}, \mathrm{Y}^{\mathrm{e}^{0}}\right.$ ) such that $u(0)=U\left(\bar{l}-\ell\left(p^{0}, \pi\left(p^{0}, Y^{e^{0}}\right)\right), c_{1}\left(p^{0}, \pi\left(p^{0}, Y^{e^{0}}\right)\right), c_{2}\left(p^{0}, \pi\left(p^{0}, Y^{e^{0}}\right)\right)\right)<\mathscr{U}\left(Y^{e^{*}}\right)$, then the system converges to an equilibrium $\left(\hat{P}, \hat{Y}^{e}\right)$ with $\mathscr{U}\left(\hat{Y}^{e}\right)<\mathscr{U}\left(\mathrm{Y}^{e^{*}}\right)$ or to the boundary point $\left(0, \sqrt{\mathrm{k}_{1} \mathrm{~b}(0)}, 0,0\right)$ and utility level $\mathrm{U}(\bar{l}, 0,0)$. Theorem 4 shows that there also exist points $\left(\mathrm{P}^{0}, \mathrm{Y}^{\mathrm{e}^{0}}\right) \in \mathrm{R}$ such that $\mathrm{u}(0)>\mathfrak{A}\left(\mathrm{Y}^{\mathrm{e}^{*}}\right)$ but $\lim u(t)<\mathscr{U}\left(Y^{e^{*}}\right)$. $t \rightarrow \infty$

Theorem 4. (Convergence to inferior positions)

a. If $\left(\mathrm{P}^{0}, \mathrm{Y}^{\mathrm{e}^{0}}\right)$ is such that $\mathrm{u}(0)<\mathfrak{U}\left(\mathrm{Y}^{\mathrm{e}^{*}}\right)$ or if $\left(\mathrm{P}^{0}, \mathrm{Y}^{\mathrm{e}^{0}}\right)$ satisfies $\mathrm{u}(0)=2\left(\mathrm{Y}^{\mathrm{e}^{*}}\right)$ but either $\mathrm{P}^{0} \neq \beta\left(\mathrm{Y}^{\mathrm{e}^{*}}\right) \mathrm{p}^{*}$ or $\mathrm{p}^{0}=\beta\left(\mathrm{Y}^{\mathrm{e}^{*}}\right) \mathrm{P}^{*}$ and $\mathrm{Y}^{\mathrm{e}^{0}}<\mathrm{Y}^{\mathrm{e}^{*}}$, then the solution path converges to $\left(\hat{\mathrm{p}}, \hat{\mathrm{Y}}^{\mathrm{e}}\right) \in E\left(\mathrm{p}^{0}, \mathrm{Y}^{\mathrm{e}^{0}}\right)$ with $\hat{Y}^{e}<Y^{e^{*}}$ (and hence $\mathscr{U}\left(\hat{Y}^{e}\right)<थ\left(Y^{e^{*}}\right)$ ) or to $\left(0, \sqrt{k_{1} b(0)}, 0,0\right)$ (with utility level $\mathrm{U}(\bar{l}, 0,0)$ ).

b: There exist $\left(p^{0}, Y^{e^{0}}\right) \in R$ such that $u(0)>\mathscr{U}\left(Y^{e^{*}}\right)$ but $\lim _{t \rightarrow \infty} u(t)<\mathscr{U}\left(Y^{e^{*}}\right)$.

Proof: The proof of a is immediate from the result in the proof of Theorem 3 that $u(t)$ is strictly decreasing unless either $\left(p(t), Y^{e}(t)\right)$ is an equilibrium or $P(t)=\beta\left(Y^{e^{*}}\right) P^{*}$ and $Y^{e}(t)>Y^{e^{*}}$. The proof of $b$ is as follows.

Choose any $\mathrm{Y}^{\mathrm{e}} \in\left(0, \mathrm{Y}^{\mathrm{e}^{*}}\right)$ and for the remainder of the proof, denote $\overrightarrow{\mathrm{p}}\left(\mathrm{Y}^{\mathrm{e}}\right)$ by $\overline{\mathrm{p}}$. By Theorem $2, \mathscr{U}\left(\mathrm{Y}^{\mathrm{e}}\right)<\mathscr{U}\left(\mathrm{Y}^{e^{*}}\right)$. A1-A2 above imply that for $\tilde{\mathrm{Y}}^{\mathrm{e}}$ such that $\tilde{\mathrm{Y}}^{\mathrm{e}}=\mathrm{F}_{1}\left(\mathrm{~T}_{1}(\overline{\mathrm{p}})\right)$, 


$$
\mathscr{N}\left(\mathrm{Y}^{\mathrm{e}^{*}}\right)<U\left(\overline{\mathrm{l}}-\ell\left(\overline{\mathrm{p}}, \pi\left(\overline{\mathrm{p}}, \tilde{\mathrm{Y}}^{\mathrm{e}}\right)\right), c_{1}\left(\overline{\mathrm{p}}, \pi\left(\overline{\mathrm{p}}, \tilde{\mathrm{Y}}^{\mathrm{e}}\right)\right), c_{2}\left(\overline{\mathrm{p}}, \pi\left(\overline{\mathrm{p}}, \tilde{\mathrm{Y}}^{\mathrm{e}}\right)\right)\right) .^{21}
$$

Hence, by a famfliar continuity argument, there exists $\mathrm{Y}^{e^{\prime}}, \mathrm{Y}^{\mathrm{e}}<\mathrm{Y}^{\mathrm{e}^{\prime}}<\mathrm{Y}^{e}$,

such that

$$
\mathscr{2}\left(\mathrm{Y}^{\mathrm{e}^{*}}\right)=\mathrm{U}\left(\overline{\mathrm{l}}-\ell\left(\overline{\mathrm{p}}, \pi\left(\overline{\mathrm{p}}, \mathrm{Y}^{\mathrm{e}^{\prime}}\right)\right), c_{1}\left(\overline{\mathrm{p}}, \pi\left(\overline{\mathrm{p}}, \mathrm{Y}^{\mathrm{e}^{\prime}}\right)\right), c_{2}\left(\overline{\mathrm{p}}, \pi\left(\overline{\mathrm{p}}, \mathrm{Y}^{\mathrm{e}^{\prime}}\right)\right)\right) .
$$

By appeal to part a of the present theorem, this implies that when $\left(\mathrm{P}(0), \mathrm{Y}^{\mathrm{e}}(0)\right)=\left(\beta \overline{\mathrm{p}}, \mathrm{Y}^{\mathrm{e}^{\prime}}\right)$ in the intertor of $\mathrm{R}, \mathrm{u}(0)=\mathfrak{X}\left(\mathrm{Y}^{\mathrm{e}^{*}}\right)$ and

$\lim u(t)<\mathscr{U}\left(Y^{e^{*}}\right)$, so that for some $t\left(Y^{e}\right), u(t)<\mathscr{N}\left(Y^{e^{*}}\right)$ for $t \geq t\left(Y^{e}\right)$. $t \rightarrow \infty$

Take any sequence $\left\{\left(\mathrm{P}^{\mathrm{k}}, \mathrm{Y}^{\mathrm{e}}\right)\right\}$ in $\mathrm{R}$ converging to this $\left(\beta \overline{\mathrm{p}}, \mathrm{Y}^{\mathrm{e}^{\prime}}\right)$. For the remainder of this proof, denote target utility as a function of $(P, Y)$ by $V(p, Y)$. Let $x^{0} \equiv\left(\beta \bar{p}, Y^{e^{\prime}}\right), x^{k} \equiv\left(p^{k}, Y^{e^{k}}\right)$. Then using the continuity of the solution path in the initial point, for any $t \geq 0$,

$$
\begin{aligned}
u\left(t ; x^{0}\right)=V\left(p\left(t ; x^{0}\right), Y^{e}\left(t ; x^{0}\right)\right) & =V\left(P\left(t ; \lim _{k \rightarrow \infty} x^{k}\right), Y^{e}\left(t ; \lim _{k \rightarrow \infty} x^{k}\right)\right) \\
& =\underset{k \rightarrow \infty}{ }\left(\lim _{k \rightarrow \infty} p\left(t ; x^{k}\right), \underset{k \rightarrow \infty}{\left.\lim _{k} Y^{e}\left(t ; x^{k}\right)\right)}\right. \\
& =\underset{k \rightarrow \infty}{ } \lim _{k \rightarrow \infty} V\left(P\left(t ; x^{k}\right), Y^{e}\left(t ; x^{k}\right)\right)=\lim _{k \rightarrow \infty} u\left(t ; x^{k}\right)
\end{aligned}
$$

(where $u(t ; x)$ is target utility as in (16) but with dependence on the initial point shown explicitly). This last implies that for some $K>0, k \geq K$ implies $u\left(t ; x^{k}\right)<\mathscr{N}\left(Y^{e^{*}}\right)$ for $t \geq t\left(Y^{e}\right)$. But this implies that there exists an open set $N\left(Y^{e}\right) \subset R,\left(\beta \bar{p}, Y^{e^{\prime}}\right) \in N\left(Y^{e}\right)$, such that $\left(p^{0}, Y^{e^{0}}\right) \in N\left(Y^{e}\right)$ implies

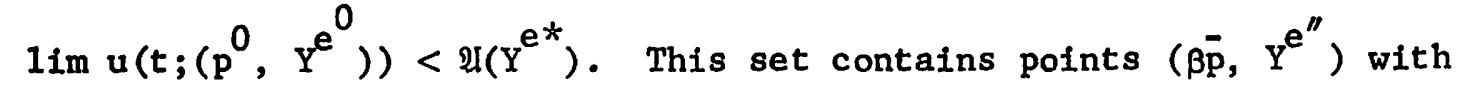
$t \rightarrow \infty$

$\mathrm{Y}^{\mathrm{e}^{\prime \prime}}>\mathrm{Y}^{\mathrm{e}^{\prime}}$ and therefore $\mathrm{u}\left(0 ;\left(\beta \overline{\mathrm{p}}, \mathrm{Y}^{\mathrm{e}^{\prime \prime}}\right)\right)>\mathscr{U}\left(\mathrm{Y}^{\mathrm{e}^{*}}\right)$ (in fact, there are open sets within $N\left(Y^{e}\right)$ containing points $(\mathrm{P}, \mathrm{Y})$ with $\mathrm{p} \neq \beta \overline{\mathrm{p}}, \mathrm{Y}>\mathrm{Y}^{\mathrm{e}^{\prime}}$ such that $\left.u(0 ;(p, Y))>\mathfrak{U}\left(Y^{e^{*}}\right)\right)$ and hence, the proof of part $b$ is complete. $\square$ 
Theorem 4 and its proof indicate that starting from a variety of subsets of $R$, the economy converges to inferior positions. The most intuitive case is the one of [more or less] self-fulfilling expectations mentioned in the Introduction: If expectations in the aggregate are pessimistic and if relative prices are near the equilibrium relativeprice vector which would cause household behavior to exactly confirm these pessimistic expectations, then the economy converges to a Paretoinferior position. In terms of the formal model, for any $\mathrm{Y}^{\mathrm{e}} \in\left(0, \mathrm{Y}^{\mathrm{e}}\right)$, there exists an open set $s \subset\left\{p \in \Omega_{++}^{3}: \sum_{i=0}^{2} \frac{p_{i}^{2}}{k_{i}} \leq b\right\}$ containing the set $\left\{p \in \Omega_{++}^{3}: \sum_{1=0}^{2} \frac{p_{1}^{2}}{k_{1}}<b\right.$ and $\left.p=\beta \bar{p}\left(Y^{e}\right), \beta>0\right\}$, such that for $\left(p(0), Y^{e}(0)\right) \in \operatorname{Sx}\left\{Y^{e}\right\}$, $\lim _{t \rightarrow \infty} U\left(\bar{l}-\ell(p(t), \pi(t)), c_{1}(p(t), \pi(t)), c_{2}(p(t), \pi(t))\right)<2\left(Y^{e^{*}}\right)$. 


\section{FOOTNOTES}

* This paper was completed while the author was at the University of Western Ontario. Helpful comments and criticisms by Peter Howitt, Michael Parkin and Charlie Stuart on earlier drafts are gratefully acknowledged.

$\left.I_{\text {Hahn ( }}[4],[5]\right)$ and Salop [6] study the existence of such equilibria in static models with flexible prices. Varian ([9], Section 2) presents a dynamic model in which an atomistic economy with flexible prices can get stuck. Eckalbar ([3], Section V) presents a model very similar to Varian's but does not explicitly consider convergence to inferior equilibria.

The Varian and Eckalbar models are closely related to the model in the present paper. However, these models differ from the one in the present paper in that the particular dynamic adjustment specifications used by Varian and Eckalbar together with the fact that their models involve only two goods (labor and output) result in an attenuated role for price flexibility and economies which are structurally prone to getting stuck in inferior equilibria. (In [9], Section 3, Varian extends his two good model to one with $n$ productive factors but with assumptions such that the characterization above still holds.) In Varian's model, this is reflected in the fact that 1) whenever the real wage is below the Walrasian equilibrium level and the sales expectation constraint is not binding, there is excess supply of output, and 2) whenever the real wage is below the Walrasian equilibrium level and the level of sales expectations is below the Walrasian equilibrium level of output, the economy must converge to the inferior equilibrium. In Eckalbar's model, the expectation adjustment specifications imply that sales expectations can never rise. 
2 The model can be extended to the case of $r$ unproduced factors of production and $n$ consumption goods. Such an extension complicates the picture but essentially adds nothing new.

${ }^{3}$ Market values are reckoned in terms of an abstract unit of account. During any one period a single price emerges for each commodity, but how prices are set is left unexplained.

${ }^{4}$ of course, producers of good two and households have similar incentives. For the sake of simplicity, the assumption is made that only the sales expectations of firms producing good one enter the picture. The extension to the case of all producers having sales expectations does not alter the basic thrust of the results. One anticipates that this will also be true of extensions which incorporate other quantity or price expectations.

${ }^{5}$ In a different setting, Turnovsky [7] has shown that adaptive expectations with a variable adjustment coefficient can be rational in the sense of arising from a Bayesian decision process. The question regarding the extent to which expectations in the present model are rational is left open, but Turnovsky's result suggests that in some cases of interest, expectations in the present model are rational in the Bayesian sense of agents not wasting information.

${ }^{6}$ The continuous time process below should not be considered as a limiting case for a sequence of discrete time processes (see Burmeister and Turnovsky [2]).

${ }^{7}$ These terms receive precise definition in Sections two and three below. 
${ }^{8}$ Notational conventions: $R^{\mathrm{n}}$ denotes $\mathrm{n}$-dimensional Euclidean space, $\Omega^{n}$ denotes the nonnegative orthant of $R^{n}$ $\Omega_{+}^{n}=\left\{r \in \Omega^{n}: r>0\right\}, \Omega_{++}^{n}=\left\{r \in \Omega^{n}: r \gg 0\right\}, s^{n}=\left\{r \in \Omega_{+}^{n}: \sum_{i=1}^{n} r_{1}=1\right\}$, $s_{+}^{n}=\left\{r \in \Omega_{++}^{n}: \sum_{i=1}^{n} r_{i}=1\right\}$, where for $r \in Q^{n}, r \geq 0$ means that $r_{i} \geq 0$, $i=1, \ldots, n, r>0$ means that $r \geq 0, r \neq 0$, and $r \gg 0$ means that $r_{1}>0,1=1, \ldots, n$, and for two sets $X, Y, X \subset Y, Y-X=\{x \in Y: X \notin X\}$

${ }^{9}$ For notational convenience, $T_{i}$ is designated as a function of the full vector $p$, although it is nontrivially a function only of $p_{0}$ and $p_{1}$.

${ }^{10}$ This last assumption is conventional in dynamic, competitive mode1s with production. A major consequence of this assumption in the present model Is that a conventional form of Walras' Law holds.

${ }^{11}$ For this last, see Arrow and Hahn ([1], pp. 100-101.)

12 The proof of the initial statement and a involves a case by case approach to the utility maximization problem, A2 above and the type of argument given in Arrow and Hahn ([1], pp. 103-104). b follows easily from a.

${ }^{13}$ The proof of the weak axiom of revealed preference follows the lines of the proof in Arrow and Hahn ([1], p. 218). The proofs of all other statements in $a-b$ follow easily from $A 1-A 2$ and their implications listed above.

${ }^{14}$ The price adjustment specifications here differ from those of Varian ([9], Section 2) and Eckalbar ([3], Section V). In the Varian and Eckalbar models, price adjustment in the commodity market is governed by the excess commodity demand which explicitly reflects the revised (due to excess supply in the labor market) commodity demand of households or the revised (due to excess demand in the labor market) commodity supply of firms. 
${ }^{15}$ This represents a continuous time "approximation" to the discrete time process of the economy. See the discussion on p. 2 above.

${ }^{16}$ The system (8) should not be seen as representing the economic process in real time, but rather as an abstraction (in the variable $t \in[0, \infty)$ ) repre. senting the adjustment dynamics of the economy over a finite period of time. For ease of reference, the variable $t$ will continue to be called "time".

${ }^{17}$ This assumption can be deduced, by means of the implicit function theorem, from the assumption that for any fixed $\mathrm{Y}^{\mathrm{e}} \in\left(0, \mathrm{Y}^{\mathrm{e}^{*}}\right)$, the Jacobian matrix of the system (7) is nonsingular on $s_{+}^{3}$. For the sake of convenience, the desired result involving $\overline{\mathrm{p}}\left(\mathrm{Y}^{\mathrm{e}}\right)$ is simply assumed.

${ }^{18}$ See Arrow and Hahn ([1], p. 285).

${ }^{19}$ The proof of (17) represents a straightforward adaptation of the proof on p. 287 in Arrow and Hahn [1]. It involves the first order conditions for utility maximization, Walras' Law and the fact that $p_{1} F_{i}^{f}\left(T_{1}(p)\right)=p_{0}, 1=1,2$.

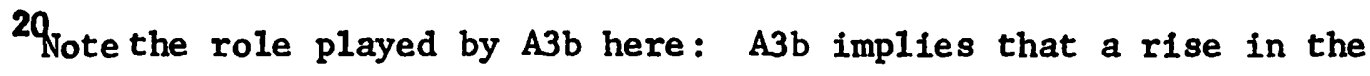
aggregate point sales expectation when this expectation effectively constrains producers of good one cannot increase the target utility of the representative household even when there is positive excess demand for good one.

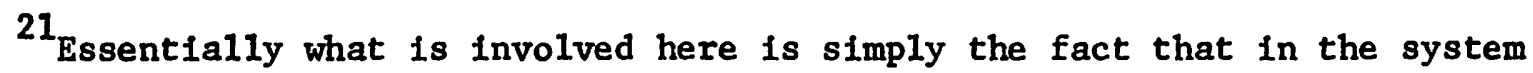
without expectations (10) above, the target utility of the representative household is minimized at $\mathrm{p}^{*}$. For an intuitive explanation of this under more restrictive assumptions regarding utility functions, see Arrow and Hahn ([1], p. 288). 


\section{REFERENCES}

[1] Arrow, K. J. and F. H. Hahn, General Competitive Analysis, (Holden-Day, 1971).

[2] Burmeister, E. and S. J. Turnovsky, "The Specification of Adaptive

Expectations in Continuous Time Dynamic Economic Models," Econometrica (September, 1976).

[3] Eckalbar, J. C., "The Stability of Non-Walrasian Processes: Two Examples," unpublished manuscript (February, 1978).

[4] Hahn, F., "On Non-Walrasian Equilibria," Technical Report No. 203, The Economic Series, Institute for Mathmetical Studies in the Social Sciences, Stanford University (April, 1976).

[5] Hahn, F., "Unsatisfactory Equilibria," Technical Report No. 247, The Economic:" Series, Institute for Mathematical Studies in the Soclal Sciences, Stanford University (September, 1977).

[6] Salop, S. C., "Rational Expectations and Multiple Equilibria: Love, Faith, Money and Underemployment," Special Studies Paper Number 106--Division of Research and Statistics, Federal Reserve Board, Washington, D.C. (February, 1978).

[7] Turnovsky, S. J., "A Bayesian Approach to the Theory of Expectations," Journal of Economic Theory (August, 1969).

[8] Uzawa, H., "The Stability of Dynamic Processes," Econometrica (October, 1961).

[9] Varian, H., "Non-Walrasian Equilibria," Econometrica (Apri1, 1977). 